\title{
Influence of sexual experience and social environment on fertility and incidence of mating in young female bank voles (Clethrionomys glareolus)
}

\author{
Lilian M. Westlin and T. O. Gustafsson \\ Department of Zoology, University of Lund, S-223 62 Lund, Sweden
}

\begin{abstract}
Summary. Between 30 and 40 days of age, female bank voles were kept singly, in female pairs, separated from an adult male by a wire mesh, or paired with a vasectomized male. At Day 40 they were paired with adult intact males. Fertility at the first mating was low $(22-25 \%)$, but if the females had previously mated with the vasectomized male fertility of the subsequent mating with the intact male was significantly increased $(63 \%)$. Sterile matings therefore had a priming effect on the females, and could be important for the development of puberty in wild females.

Only $55-59 \%$ of the females without contact with males between Days 30 and 40 mated with the fertile male. Contact with a male through a wire mesh increased the proportion to $80 \%$ and co-habitation with a vasectomized male to $94 \%$. In the last group, mating also occurred at a younger age.
\end{abstract}

\section{Introduction}

It is often assumed that infertile matings are rarely found in wild small mammals (Conaway, 1971). In microtine rodents, however, infertile matings at the beginning of the breeding season may be a general phenomenon because non-functional corpora lutea have been observed in Microtus agrestis (Brambell \& Hall, 1939; Westlin, 1982a), M. pennsylvanicus (Mallory \& Clulow, 1977), $M$. californicus (Greenwald, 1956), M. pinetorum (Kirkpatrick \& Valentine, 1970), M. oeconomus ratticeps and Clethrionomys rutilus (Hoyte, 1955), C. rufocanus (Westlin, 1982a) and C. glareolus (Westlin \& Nyholm, 1982). Some of these authors have attributed non-functional corpora lutea to spontaneous ovulations, but it is now generally accepted that microtines are reflex ovulators (Breed, 1967, 1972; Clarke, Clulow \& Greig, 1970; Milligan, 1975; Westlin \& Nyholm, 1982).

In bank voles ( $C$. glareolus) infertility occurs in adult females at the beginning of the breeding season, and also in female young of the same year at their first matings (Westlin \& Nyholm, 1982). The infertility may therefore be a phenomenon of puberty; the beginning of the breeding season has been compared with puberty (Hutchinson \& Sharp, 1977).

Under laboratory conditions, young female bank voles mated with fully fertile males frequently fail to become pregnant (Westlin \& Nyholm, 1982). The infertility is associated with low activity of the corpora lutea and the fertilized eggs will never implant (Westlin \& Nyholm, 1982).

Treatment of recently mated females with progesterone increases fertility to $100 \%$ without activating the corpora lutea. The activation of corpora lutea is dependent on prolactin: injections of exogenous prolactin result in activation of corpora lutea and dramatically increase fertility $(93 \%$ compared to $35 \%$ in untreated young females) (Westlin, 1982b). It is possible that sterile matings may prime the females and thus increase fertility of subsequent matings.

This work aimed to study this possible priming effect of sterile matings on fertility. The effect of proximity to a male during puberty on fertility was also investigated. 


\section{Materials and Methods}

The bank voles (Clethrionomys glareolus) were from the laboratory colony kept at the Department of Zoology, University of Lund, Sweden (Gustafsson, Andersson \& Westlin, 1980). They were housed in standard plastic cages with wire mesh lids and with wood shavings as litter. They were fed a commercial mouse food supplemented once a week with guinea-pig food. The photoperiod was $18 \mathrm{~h}$ light : $6 \mathrm{~h}$ dark, lights on $03: 00 \mathrm{~h}$. The 186 females were kept in groups of 5 from weaning at Day 18 until the start of the experiment, when they were assigned randomly to the various treatments (Table 1). Between the ages of 30 and 40 days, the voles were housed singly (Group A), housed 2 females per cage (Group B), housed 1 female and 1 male per cage, separated by a wire mesh (Group C), or housed 1 female and 1 vasectomized male per cage (Group D). The size of cages was $20 \times 40 \times 15 \mathrm{~cm}$ in Groups A, B and D, and $35 \times 55 \times 20 \mathrm{~cm}$ in Group C. The females in Group D were checked for vaginal plugs twice daily, at approximately 12-h intervals. To avoid experimental errors, the females in the other groups were treated similarly. When 40 days old, each female was placed in a clean cage and paired with a sexually experienced intact male. They were checked for vaginal plugs twice daily as above. The male was removed 1 day after a vaginal plug was found. The females were autopsied 6 days after mating, and the weights of ovaries and uteri and the incidence of pregnancy were recorded. At this time, the embryos are visible as 3-4 mm swellings (Andersson \& Gustafsson, 1979). The number and macroscopic appearance of corpora lutea were noted. If no vaginal plug was found before Day 60, the female was autopsied as above.

The G test of independence (Sokal \& Rohlf, 1969) and Mann-Witney U test were chosen for statistics.

Day 30 to 40 of age

\section{Results}

Copulatory plugs were found in $28(53 \%)$ of the 53 females in Group D. In 5 of these females, two matings with the vasectomized male were recorded.

Day 40 to 60 of age

A much higher proportion of matings with fertile males was found in the females in Group D than in females in Groups A and B (Table 1). Females in Group C had intermediate values. In Group D no difference in the proportion mating was found between females which earlier had

Table 1. Incidence of mating and fertility of matings in female bank voles kept in different social environments between Days 30 and 40 of age, and thereafter paired with normal males

\begin{tabular}{|c|c|c|c|c|}
\hline Group (treatment, Days 30-40) & $\begin{array}{l}\text { No. of } \\
\text { females }\end{array}$ & $\begin{array}{c}\text { No. }(\%) \\
\text { mated with } \\
\text { normal male }\end{array}$ & $\begin{array}{c}\text { No. }(\%) \\
\text { of females } \\
\text { pregnant }\end{array}$ & $\begin{array}{c}\text { Total } \\
\text { fertility } \\
(\%)\end{array}$ \\
\hline A (1 female/cage $)$ & 44 & $24\left(55^{\mathrm{a}, \mathrm{b}}\right)$ & $6\left(25^{d}\right)$ & 14 \\
\hline B (2 females/cage $)$ & 39 & $23\left(59^{a}\right)$ & $5\left(22^{c}\right)$ & 13 \\
\hline C (normal male, separated by net) & 50 & $40(80)$ & $10\left(25^{c}\right)$ & 20 \\
\hline D (vasectomized male) & 53 & $50(94)$ & $21\left(42^{\mathrm{e}}\right)$ & 40 \\
\hline $\mathrm{D}_{\mathrm{l}}$ (no mating with vasectomized male)* & 25 & $23(92)$ & $4\left(17^{c}\right)$ & 16 \\
\hline $\mathrm{D}_{\mathrm{Y}}$ (mating with vasectomized male) ${ }^{*}$ & 28 & $27(96)$ & $17(63)$ & 61 \\
\hline
\end{tabular}

\footnotetext{
* Subdivisions of Group D.

a Lower than Group D, $P<0.001$.

bower than Group C, $P<0.025$.

c Lower than Group $\mathrm{D}_{\mathrm{M} 1}, P<0.01$.

'Lower than Group $\mathrm{D}_{\mathrm{M}}, P<0.025$.

' Higher than Groups A, B \& C combined, $P<0.05$.
} 
mated with a vasectomized male $\left(D_{M}\right)$ and those which had not $\left(D_{U}\right)$ (Table 1). Of the 137 mated females, 37 were visibly pregnant, 2 had small placental scars (one each in Groups $A$ and $D_{M}$ ) and 3 were classified as pseudopregnant (all in Group D). Like pregnant females, the pseudopregnant females had activated large pink corpora lutea and their ovarian weights were also similar to those of pregnant females but the reason for the pseudopregnancy is obscure; all 3 females had mated with a vasectomized male $1-2$ days before mating with the normal male. The females with placental scars evidently had had corpora lutea which were active enough to initiate implantation.

Infertility in young female bank voles is due to lack of activation of the corpora lutea (Westlin \& Nyholm, 1982; Westlin, 1982b). Because the above 5 females all showed evidence of activation of the corpora lutea, they were considered to have had fertile matings.

Fertility was similar in Groups A, B and C but was significantly higher in Group D (Table 1). Within Group D the fertility was dependent on previous mating experience: females which had mated with the vasectomized male (Group $D_{M}$ ) showed much higher fertility after the subsequent mating with the normal male (Table 1 ) than did the unmated females (Group $D_{U}$ ). Within Group $\mathrm{D}_{\mathrm{M}}$, the few females with two recorded matings with the vasectomized male showed a higher fertility (4 out of 5) than did those with only one mating (13 out of 22). Even if the pseudopregnant females and those with placental scars were regarded as non-pregnant, the fertility of Group $D_{M}$ females would still be significantly higher than that of Groups A, B and C $(P<0.025, \mathrm{G}$ test of independence).

The treatments also affected the age at which mating occurred (Text-fig. 1). Animals kept with a vasectomized male mated with the normal male at a younger age than did those kept singly or in groups of two females (Mann-Witney $\mathrm{U}$ test, $P<0.01$ and $P<0.05$ respectively). Again, females in Group $\mathrm{C}$ mated at intermediate ages.
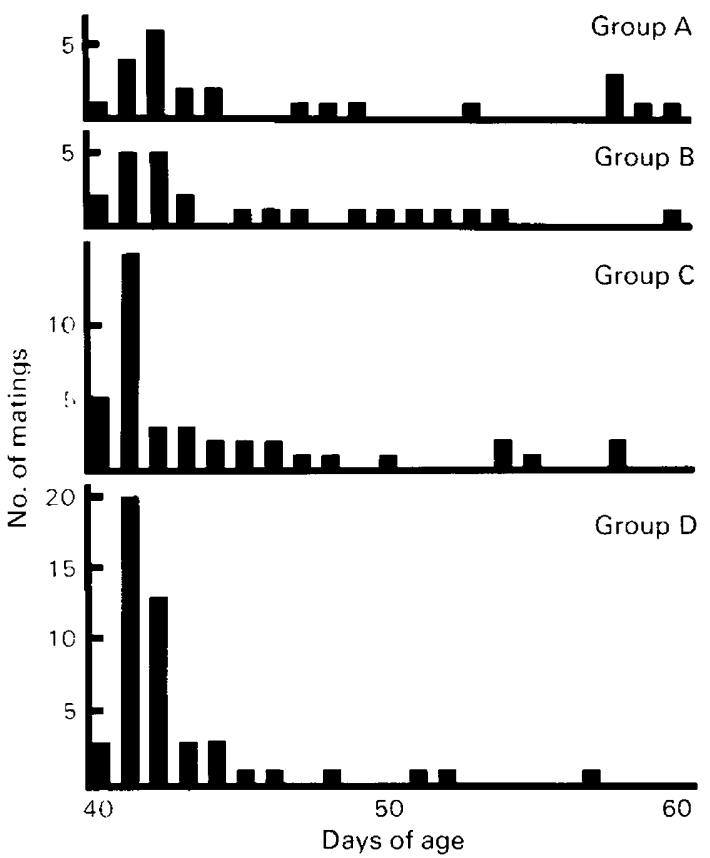

Text-fig. 1. Time of mating in female bank voles, kept in different social environments between Days 30 and 40 of age, and then paired with sexually experienced males. Group A, kept singly; Group B, 2 females kept together; Group C, separated from a normal male by a net barrier; Group D, with a vasectomized male. 


\section{Discussion}

Many small rodents show oestrus 1-2 days after introduction of an adult male. In microtines this has been reported for prairie voles, M. ochrogaster (Hasler \& Conaway, 1973; Carter, Getz, Gavish, McDermott \& Arnold, 1980). Male-induced oestrus occurred in this study. In all groups, there was a peak in the number of matings 2-3 days after the pairing with the normal male (Text-fig. 1). After the initial peak comparatively few matings were seen. Carter et al. (1980) reported that female prairie voles kept with sibling males failed to reach oestrus and the females did not respond to odours of the sibling males. However, if sibling male urine was applied to the nostrils, the females rapidly reached oestrus and mated with the sibs. Carter et al. (1980) considered that the failure to reach oestrus was due to lack of naso-genital grooming between siblings. These findings may also apply to bank voles. If the female is not mature enough to respond immediately to the male, she may develop a sibling-like relationship to the male, and be relatively unlikely to reach oestrus, even when mature. Such a relationship would be broken and an oestrus induced if a new male was introduced. This occurred in Groups $\mathrm{C}$ and $\mathrm{D}$, in which contact with an unknown male resulted in induction of oestrus and a high incidence of mating 2-3 days later, in spite of the fact that they had already been in contact with adult males.

Physical or olfactory contact with a male accelerates puberty in prairie voles (Hasler \& Nalbandov, 1974; Carter et al., 1980) and lemmings, Dicrostonyx groenlandicus (Hasler, 1974). In Groups C and D a much higher proportion of the females mated on Days 40-44 than in Groups A and B ( 82 and $56 \%$ compared with 35 and $34 \%$ respectively). This may be explained by a maleinduced acceleration of puberty, resulting in a larger number of females being mature enough to respond with oestrus to the new male.

The increased fertility in Group D seems to be a direct response to mating with a vasectomized male, because the effect was shown only in Group $D_{M}$ females. It may be argued that the experimental design could cause the most fertile females to be selected into Group $D_{M}$. This is an unlikely explanation, because the proportion of females mating with the vasectomized male is very similar to the proportions mating in Groups $\mathbf{A}$ and $\mathbf{B}$.

The occurrence of sterile matings in wild populations (Westlin \& Nyholm, 1982) indicates that these are a natural part of the maturation process both at puberty and in females 're-maturing' after the winter anoestrus. The priming effect of sterile matings found here indicates that such matings are important in accelerating maturation of the females.

This study was financed by grants from the Swedish Natural Science Research Council and from the Royal Physiographic Society, Lund.

\section{References}

Andersson, C.B. \& Gustafsson, T.O. (1979) Delayed implantation in lactating bank voles, Clethrionomys glareolus. J. Reprod. Fert. 57, 349-352.

Brambell, F.W.R. \& Hall, K. (1939) Reproduction in the field vole, Microtus agrestis hirtus Bellamy. Proc. zool. Soc. Lond. 109, 133-138.

Breed, W.G. (1967) Ovulation in the genus Microtus. Nature, Lond. 214, 826.

Breed, W.G. (1972) The question of induced ovulation in wild voles, Microtus agrestis. J. Mammal. 53, 185187.

Carter, C.S., Getz, L.L., Gavish, L., McDermott, J.L. \& Arnold, P. (1980) Male-related pheromones and the activation of female reproduction in the prairie vole (Microtus ochrogaster). Biol. Reprod. 23, 10381045.

Clarke, J.R., Clulow, F.V. \& Greig, F. (1970) Ovulation in the bank vole, Clethrionomys glareolus. J. Reprod. Fert. 25, 531, Abstr.

Conaway, C.H. (1971) Ecological adaptation and mammalian reproduction. Biol. Reprod. 4, 239-247.

Greenwald, G.S. (1956) The reproductive cycle of the field mouse, Microtus californicus. J. Mammal. 37, 213-222.

Gustafsson, T.O., Andersson, C.B. \& Westlin, L.M. (1980) Reproduction in a laboratory colony of bank voles, Clethrionomys glareolus. Can.J. Zool. 58, 1016 1021 .

Hasler, J.F. (1974) Reproduction of the collared lemming, Dicrostonyx groenlandicus. Ph.D thesis, University of Illinois, Urbana.

Hasler, M.J. \& Conaway, C.H. (1973) The effect of males on the reproductive state of female Microtus ochrogaster. Biol. Reprod. 9, 426-436. 
Hasler, M.J. \& Nalbandov, A.V. (1974) The effect of weanling and adult males on sexual maturation in female voles (Microtus ochrogaster). Gen. comp. Endocr. 23, 237-238.

Hoyte, H.M.D. (1955) Observations on reproduction in some small mammals of arctic Norway. J. Anim. Ecol. 24, 412-425.

Hutchinson, J.S.M. \& Sharp, P.J. (1977) Hypothalamuspituitary control of the ovary. In The Ovary, 2nd edn, vol. 3, pp. 227-303. Eds S. Zuckerman \& B. J. Weir. Academic Press, New York.

Kirkpatrick, R.L. \& Valentine, G.L. (1970) Reproduction in captive pine voles, Microtus pinetorum. J. Mammal. 51, 779-785.

Mallory, F.F. \& Clulow, F.V. (1977) Evidence of pregnancy failure in the wild meadow vole, Microtus pennsylvanicus. Can. J. Zool. 55, 1-17.
Milligan, S.R. (1975) Mating, ovulation and corpus luteum function in the vole, Microtus agrestis. $J$. Reprod. Fert. 42, 35-44.

Sokal, R.R. \& Rohlf, F.J. (1969) Biometry. W. H. Freeman and Company, San Fransisco.

Westlin, L.M. (1982a) Sterile matings at the beginning of the breeding season in Clethrionomys rufocanus and Microtus agrestis. Can. J. Zool. 60, 2568-2571.

Westlin, L.M. (1982b) Increased fertility in young primiparous female bank voles, Clethrionomys glareolus, treated with prolactin or progesterone after mating. J. Reprod. Fert. 66, 113-115.

Westlin, L.M. \& Nyholm, E. (1982) Sterile matings initiate the breeding season in the bank vole, Clethrionomys glareolus. A field and laboratory study. Can. J. Zool. 60, 387-391.

Received 18 January 1983 